\title{
Challenges and Opportunities in Establishing a Collegiate Mentoring Program ${ }^{1}$
}

\author{
Emily Rickerson, Matthew Ohlson, Kate Fogarty, and Muthusami Kumaran²
}

Developing a new program can present many challenges at any level. Staying focused on the goal at hand and looking for successful opportunities for the program can help in getting past these barriers. Knowing what challenges may arise and ways to deal with these obstacles before the process begins is helpful. Being prepared for such challenges can make development of a program quicker and smoother for everyone involved.

Depending on the community, the stakeholders involved, and the type of mentoring program and its stage of development, different challenges may arise. Some of these challenges in the developmental stages include the following:

- Naysayers-people may not believe in the program or think there is a need. For example, some may say that there is no need for a mentoring program because they already have one in the community such as "Big Brothers, Big Sisters" (a nationwide nonprofit mentoring program).

- Time constraints-developing a program may take years to plan and implement all the steps. In college/university settings students and others involved may not be around long enough to help in the entire process due to graduation and other factors.

There are several ways to deal with these challenges. Here are some suggested solutions/opportunities for dealing with the aforementioned obstacles:
- Have a case of support statement developed before talking with administration and other stakeholders about the program. This statement should include a description of the program, the services it provides, need for the program, mission, and the benefits it provides to clients, community and society (Herman \& Associates, 2005).

- Develop a timeline of planned activities including who will be involved and when certain stages of the process should be completed. This will keep the development course stay on track and hold people responsible for getting tasks accomplished on time.

As the mentoring program moves along in its development and it comes time to start the mentoring process, challenges specific to participants of the program are likely to arise. Some overarching problems faced by mentoring programs have included the following:

- Difficulty recruiting mentors-potential mentors may lack time, resources, and interest in serving a particular community.

- Mentees not accepting their mentors-this is possibly due to socioeconomic status and racial or ethnic differences or general lack of rapport.

1. This document is FCS9268, one in a series of the Department of Family, Youth and Community of Sciences, Florida Cooperative Extension Service, Institute of Food and Agricultural Sciences, University of Florida. Published August 2011. Visit the EDIS website at http://edis.ifas.ufl.edu.

2. Emily Rickerson, graduate assistant, Department of Family, Youth and Community Sciences; Matthew Ohlson, instructional leader, Florida Virtual School, and director, CAMP Gator; Kate Fogarty, assistant professor, and Muthusami Kumaran, assistant professor, both of the Department of Family, Youth and Community Sciences; University of Florida; Gainesville, FL 32611. 
- Mentors losing interest in mentoring-for example, they start strong but become overinvested elsewhere or the program does not meet their initial expectations.

- Sporadic attendance and participation by mentor and/ or mentee result in a disconnect between the two participants and between these participants and the program.

However, there are a number of opportunities that any given collegiate mentoring program may have that can help to alleviate these challenges:

- Student mentors receive academic credit for participation in the program.

- Student mentors receive recognition for evaluated accomplishments (e.g., student mentee gains in academic performance) and gain a sense of pride in making a difference in the lives of the children they serve.

- Student mentors are viewed in the community as someone of significance because they come from local accredited colleges/universities (for example, they may be student athletes in N.C.A.A. institutions).

- Mentors receive support and guidance from teachers, school administrators, and their peers. They are also provided with various activities and structured learning objectives that are to be accomplished throughout the process to keep the mentoring sessions diverse and goal oriented, thus keeping both mentor and mentee interested.

- Attendance of student mentors to all mentoring sessions and class sessions as a course requirement. Credit will not be awarded to those who fail to meet the academic and service standards established by the school/instructor. Therefore, mentors have an even stronger initial push to show up for the mentoring sessions than most mentoring programs. It's expected that although initial participation in the program by college student mentors may be extrinsic, the sense of connection with the program, sense of accomplishment, and relationships formed with mentees will become intrinsic motivators for participation.

- Providing a structured timeline for mentor and mentee-inclusive of a timeline for meeting dates, an outline of expectations, and a list of measurable objectives of the program-will help all participants feel more comfortable in their roles.
There are other unforeseen challenges that may arise in the planning and implementation process of creating a collegiate mentoring program. Such challenges vary depending on the caliber of student, level of support at the university, demographics of the university community and community served. What's important is staying focused on the goals and objectives of the program, addressing legitimate larger concerns of the naysayers while ignoring "the small stuff," and being as prepared as possible for the challenges and rewards ahead. Giving oneself time and support from those who are a part of the program and believe in it (garnering administrative support is especially important) will help in dealing with unforeseen obstacles that arise.

\section{References}

Herman \& Associates. (2005). The Jossey-Bass Handbook of Nonprofit Leadership \& Management (second edition). San Francisco, CA: John Wiley \& Sons, Inc.

Ohlson, M. (2009). C.A.M.P. Gator: Collegiate Achievement Mentoring Program. Journal for Civic Commitment 13(1). 